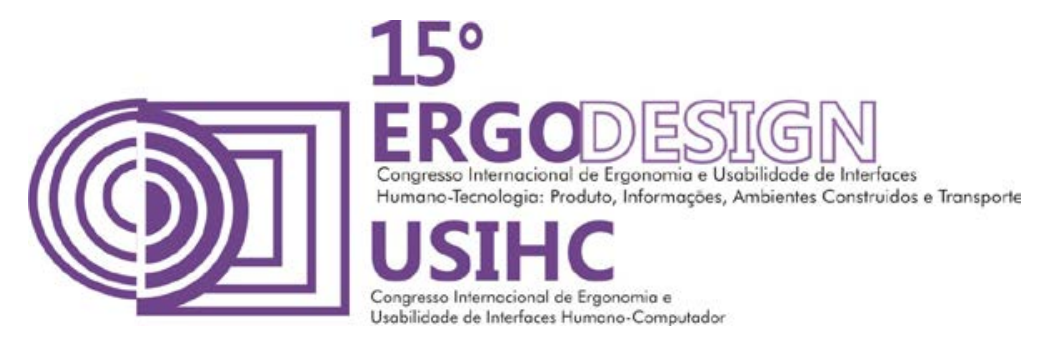

\title{
UMA REFLEXÃO SOBRE A SUBJETIVIDADE EM PROCESSOS CRIATIVOS DO DESIGN E DA ARQUITETURA
}

\section{THINKING ABOUT SUBJECTIVITY INTO CREATIVE PROCESSES RELATED TO DESIGN AND ARCHITECTURE}

\author{
MARTINS, Miguel Cañas (1) \\ EVERLING, Marli Teresinha (2) \\ (1) Universidade da Região de Joinville - Univille, Especialista \\ e-mail: \\ (2) Universidade da Região de Joinville - Univille, Doutorado \\ e-mail: marli.everling@gmail.com
}

\begin{abstract}
RESUMO
Este artigo visa refletir acerca dos processos criativos em design e arquitetura e suas interseções considerando contextos de imersão e de experiências para projetos de arquitetura. Para isso, esta explanação irá dissertar sobre a abordagem de alguns designers, arquitetos e artistas que coincidem na abordagem de procedimentos ou metodologias. Como resultado, a investigação visa apontar para uma abordagem sobre procedimentos em arquitetura através do olhar do design, como uma ferramenta para a produção de significado, expressão, construção de valores e conceitos em um contexto contemporâneo.
\end{abstract}

Palavras-chave: subjetividade, criatividade, design, arquitetura. 


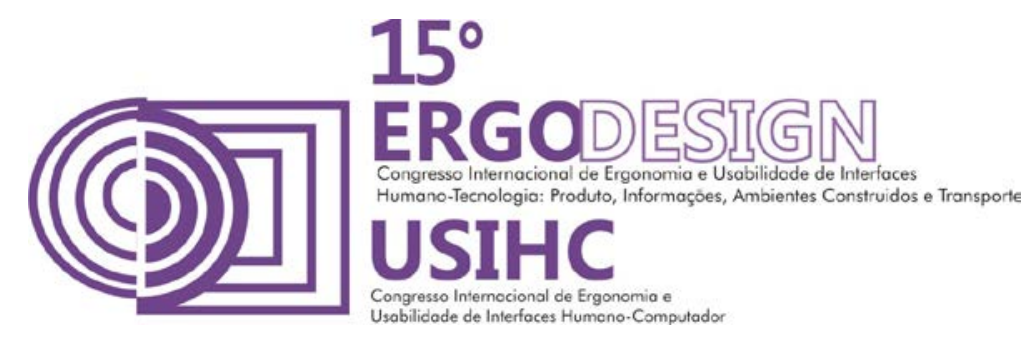

\begin{abstract}
The aim of this article is to analyse the creative processes in design and architecture and their intersections considering immersion contexts and experiences for architecture projects. For this reason, the approach will look for some designers, architects and artists whose studies coincide in procedures or methodologies. As a result, the research seeks to an approach on procedures in architecture through the eyes of design as a tool for the production of meaning, expression, building values and concepts in a contemporary context.
\end{abstract}

Keywords: Thinking about Subjectivity into Creative Processes

\title{
1. INTRODUÇÃO
}

O objetivo desta abordagem é refletir sobre a própria identidade profissional na área de arquitetura (com processos criativos muito próximas do design) considerando o papel da experiência na intersecção entre design e arquitetura. Tal inquietação resulta de uma trajetória imbuída do exercício da interdisciplinaridade e de uma movimentação profissional pessoal por ambas as áreas, tanto no campo acadêmico - como professor universitário - como na prática profissional, através do escritório de arquitetura, e da necessidade de inovação na atividade de se pensar arquitetura no contexto contemporâneo.

Enquanto educador, é importante observar que na sociedade atual, repleta de transformações constantes, é imprescindível reavaliar e adaptar as práticas docentes, deixando de lado as metodologias tradicionais. Segundo Ruberti e Pontes (2001, apud Portugal, 2013), os avanços significativos da tecnologia demandam da escola contemporânea um árduo trabalho de incorporar em suas práticas e teorias, uma nova forma de ensino-aprendizagem. No processo de formação de futuros arquitetos é preciso estar atento às novas demandas da sociedade e as possibilidades de atuação ou do diálogo desses profissionais com outros campos do saber, como por exemplo - ao que se propõe este artigo - o Design.

Como profissional, observa-se que a mútua contribuição entre as áreas é um dos pilares que sustenta uma metodologia de trabalho que vê similaridades em suas formas de pensar e que possui uma trajetória que procura acrescentar elementos, visões e raciocínios de uma área na outra, no intuito de encontrar novos meios para as soluções dos problemas de projeto. A tentativa de aproximar reflexões sobre processos nas áreas em questão busca obter uma ferramenta para a produção de significado, expressão, construção de valores e conceitos em projetos de arquitetura através do olhar do design. Conduzir a aproximação entre arquitetura e design visa promover interpretações mais imersivas nos projetos e as consequentes decodificações das informações levantadas em atributos capazes de originar linguagens específicas para o desenvolvimento de projetos de arquitetura com maior impacto reflexivo e consistência.

Investigar as relações da arquitetura, da criatividade e do design no cenário contemporâneo, considerando processos de imersão e experiência no desenvolvimento de projetos arquitetônicos, significa transitar numa área onde os limites entre arte, design, ciência e 


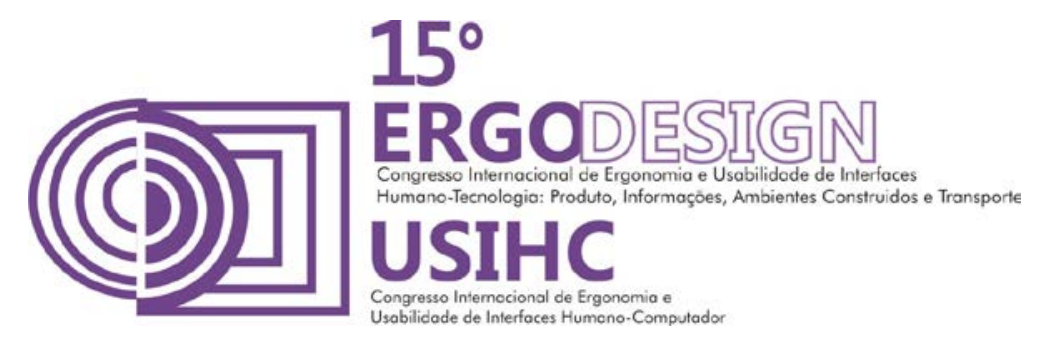

arquitetura se confundem e ajudam a dar ênfase ao papel que um artefato ou serviço desempenha na busca de uma consciência coletiva e construção de valores.

Coincide entre todas as áreas o desejo de expressão, sem importar qual seja sua vocação. Uma forma de expressão é fazendo coisas, nas quais tanto a arte, o design ou a arquitetura, utilizam-se das mesmas ferramentas, como desenhos, maquetes, esquemas, etc.

Esta caracterização corrobora com outros tipos de abordagens mais complexas, como o conhecimento sistêmico da questão. Em Cross (2004), por exemplo, essa comparação entre as áreas ainda pode ser dividida em Áreas das Ciências, Humanidades e Área dos Desenhos, demostrando que é possível considerar a existência de modos de saber, de conhecer e métodos de pesquisar que são específicos para a Área dos Desenhos: áreas que possuem o que chamou de "Modos Desenhísticos de Saber" ${ }^{1}$. As considerações de Cross trazem um tipo de pensamento também associado à arquitetura, pois têm o desenho como um recurso comum entre designers e arquitetos, em termos de expressão e organização de pensamento, fortalecendo a ideia de similaridade entre as áreas. Além do desenho como forma de pensamento e estruturação de um raciocínio, encontra-se nas mais diversas disciplinas do campo do Design aspectos que aparentam ser mais coerentes com uma abordagem de pensamento mais holístico e interdisciplinar do que na arquitetura. A Arquitetura evoluiu bastante em seu diálogo mais técnico com as engenharias. Mas o aporte teórico, técnico e ferramentas que envolvem ainda mais o usuário nos processos projetuais não progrediram como ocorreu no campo do design, como os conceitos de User Experience, Human Centerd Design ou Design Participativo.

Diante disso, este artigo visa refletir acerca dos benefícios de se explorar tais ferramentas do design em projetos arquitetônicos, buscando adicionar um novo índice à análise da tradicional lista de condicionantes que antecede todo projeto de arquitetura (programa de necessidade, o terreno, orçamento, legislação ou orientação solar). Nesta lista, a imersão na análise das relações humanas, do usuário e dos aspectos de sua interação (física ou sensorial) com o espaço, passa a ser central na discussão de um projeto que busque, através de uma experiência positiva, atender suas expectativas com eficiência, qualidade, satisfação emocional e totalidade das percepções.

\section{ARQUITETURA E ANTECEDENTES: AS RAÍZES DA DISCUSSÃO}

Durante muito tempo, ao longo da História da humanidade, a Arquitetura transitava como uma área relacionada com a Arte. Ainda hoje, para algumas organizações, está situada no limbo entre as Ciências Sociais Aplicadas e das Ciência das Exatas. O movimento deste campo do conhecimento é destacado por Biselli: O projeto de arquitetura, embora circundado de problemas técnicos e profundamente vinculado ao uso, é por natureza um processo criativo

\footnotetext{
1 Tradução de "Designerly Ways of Knowing", artigo originalmente publicado na Revista Design Studis, vol. 3, n. 4, 1982, faz parte do livro "Desenhante pensador de desenho".
} 


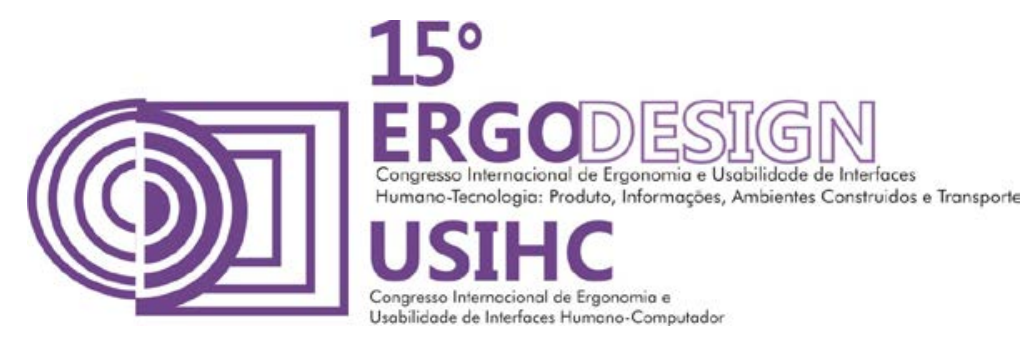

avesso a enquadramentos, formatações, metodologias ou fórmulas. Permanece, portanto, e como desde sempre, aberto à infinita inovação, ao espírito dos tempos, à antecipação de tendências, à revisão de paradigmas, e, no polo oposto, a novas visitas e itinerários interpretativos pelas tradições do passado (BISELLI, 2011, WEB). Para PIRONDI (2014) a arquitetura é um saber de fronteiras, e que ao flertar com áreas como a música, poesia, sociologia ou engenharia resulta num desenho. Mahfuz (2003, WEB) compartilha da mesma opinião ao dizer que o conteúdo artístico da arquitetura nada tem a ver com seus atributos esculturais, mas sim com a busca de sentido, propósito e intensão. São atributos de uma arquitetura que demonstra um aparente controle e coerência e que não lhe falta nem sobra nada, detentora de uma certa ordem capaz de ser identificada e valorizada, a qual não é aleatório, mas relacionada a algum aspecto objetivo do problema ou derivada de alguma questão pertinente. Sobre sentido de propósito e significado para construção que supere suas próprias dimensões físicas, Pirondi complementa: (...) Onde há o rigor necessário da técnica, sobrepomos o valor humano do sonho. A virtude da beleza. Vemos, por vezes, a arquitetura adquirir seu real significado quando cessa a função que a gerou (...). Talvez inventamos a técnica para discursarmos sobre arte. A pauta não é a música, só pode ser música se ouvida (...). Uma porta não é só dobradiça maçaneta. É um rito de passagem seletivo do corpo, um divisor entre mundos. Uma janela, um "vazio" em um muro, provavelmente tenhamos demorado milênios para abrir esses intervalos na pedra, para deixarmos passar nosso olhar, nossos sonhos, ver fora e imaginar (PIRONDI, 2014, p.29). A ideia de que arquitetura como linguagem de uma sociedade, aliada a seus instrumentos e ritos, pode justificar o motivo de ser tão difícil ensinar arquitetura, já que ao evoluir constantemente (seus saberes e fazeres), sintetiza em suas pedras os elementos constitutivos de civilizações (PIRONDI, 2014).

Tal evolução pode justificar o porquê de muitas vezes o arquiteto refletir, em meio a dificuldades de solução para um projeto, sobre seu pensamento e método que num projeto podem funcionar e em outros não. Ou seja, todo projeto é único e exige um recomeço e, neste sentido, pode ser beneficiado com abordagens de design que seja centradas no usuário, na experiência do usuário em técnicas e procedimentos imersivos.

\section{OS PROCESSOS METODOLÓGICOS EM ARQUITETURA}

No campo da arquitetura é possível verificar que em relatos sobre as técnicas e procedimentos metodológicos de diversos teóricos e profissionais da área, pouco se comenta sobre 0 envolvimento humano durante o processo criativo. Sabemos que a arquitetura é por natureza pensada para o ser humano, assim como a boa arquitetura é naturalmente sustentável. Ou seja, são conceitos inerentes à definição da palavra. Entretanto, a arquitetura está muitas vezes associada a uma ideia romântica da atividade, como o ato isolado de criação de um artista.

Para Mahfuz (2014), o conceito de qualidade em arquitetura é certamente subjetivo, podendo também significar a capacidade de criar edifícios e espaços urbanos não opressivos, voltados a vida humana. Essa subjetividade inerente à arquitetura torna difícil até mesmo sua compreensão como área produtora de significado.

Soma-se a esta falta de clareza e dificuldade - ou justamente talvez por isso - o fato de existirem diversos modelos de processos projetuais para se fazê-la. Entretanto, é possível 


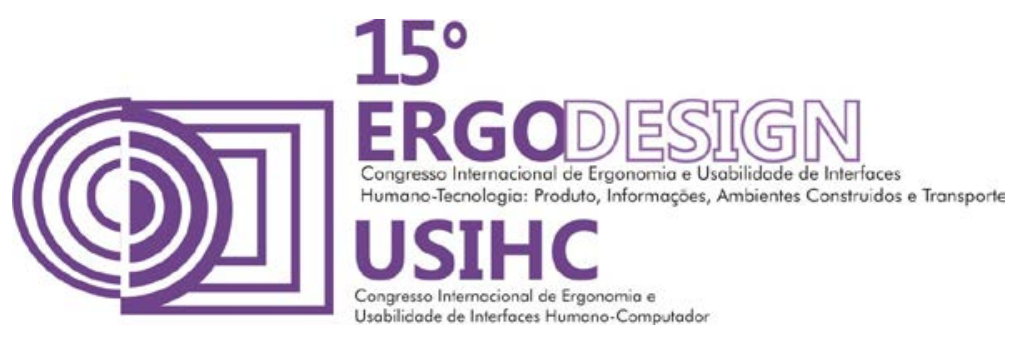

observar que no discurso entre todos os arquitetos coincide o fato de haver sempre uma "ideia central" em seus projetos, porém na maioria dos casos, individual. Além disso, a concordância com analisar tens inerentes ao projeto, como os condicionantes fundamentais de qualquer situação: programa, lugar e construção. Alguns desses exemplos de abordagens sobre metodologias veremos a seguir.

São inúmeros as tentativas em definir e explicar os processos projetuais em arquitetura e suas compreensões, as quais procuram sempre mais elucidar, ilustrar e compreender o projeto de arquitetura e o momento de adoção do partido arquitetônico. Diversos exemplos resumem 0 projeto a um processo linear de seqüência de procedimentos idêntica, como acontece em outras técnicas e disciplinas, descrito como resultado de um raciocínio lógico.

Segundo Biselli (2011) o termo projetação tem sido pouco usado no Brasil, mas é o termo que define a produção do projeto de arquitetura como um processo. Este processo tem um momento crítico, ao que denominamos "partido arquitetônico", um termo bem específico do campo da arquitetura, o que poderia equivaler ao "conceito" ou "estratégia" em outras áreas. Para o autor, "partido" é o momento de tomada de decisões específicas e compreende a discussão de aspectos primordiais como estratégia de implantação, distribuição do programa, estrutura e relações de espaço, e outros temas, secundários, relativos às atividades criativas, como composição, estilo, estética etc. É tema preponderante nas discussões entre arquitetos, como um aspecto central da teoria de projeto e de projetação, uma característica fundamental de estrutura do pensamento do profissional.

Em Biselli (2011) o autor elenca uma série de opiniões acerca das definições de partido e do processo projetual de alguns arquitetos, os quais variam pontos de vista, sendo a composição formal o mais importante ou está como consequência de uma concepção de natureza lógica da técnica. Segundo ele, Le Corbusier enfatizou ainda mais o uso da lógica matemática ao dizer que o início do processo de criação é a definição da planta arquitetônica, que por sua vez é a representação do programa arquitetônico (função da edificação). Assim, a projeção vertical da planta resultaria, segundo ele, nas paredes que por sua vez se tornariam volumes: linhas que se transformam em planos que se transformam em volumes; é a seqüência linear e crescente do raciocínio cartesiano (BISELLI, 2011, WEB).

Carlos Lemos, autor contemporâneo, faz uso de termos como "conseqüência" e "resultado", nos quais fica implícita uma ideia de lógica: Arquitetura seria, então, toda e qualquer intervenção no meio ambiente criando novos espaços, quase sempre com determinada intenção plástica, para atender a necessidades imediatas ou a expectativas programadas, e caracterizada por aquilo que chamamos de partido. Partido seria uma conseqüência formal derivada de uma série de condicionantes ou de determinantes; seria o resultado físico da intervenção sugerida (LEMOS, 2003, p. 40-41, apud BISELLI, 2011, WEB).

Biselli afirma portanto que todo arquiteto utiliza de uma lógica face a dados fornecidos para elaboração de um projeto, e que tem em sua razão de ser a justificativa, mas que essa lógica é tão variada e pessoal que é impossível de transforma-se um processo projetual em uma sistemática universal. São justamente esses modelos de projetação tão dispares que tornam o assunto tão curioso e fonte grande de interesse, pois cada arquiteto ou autor pode igualmente 


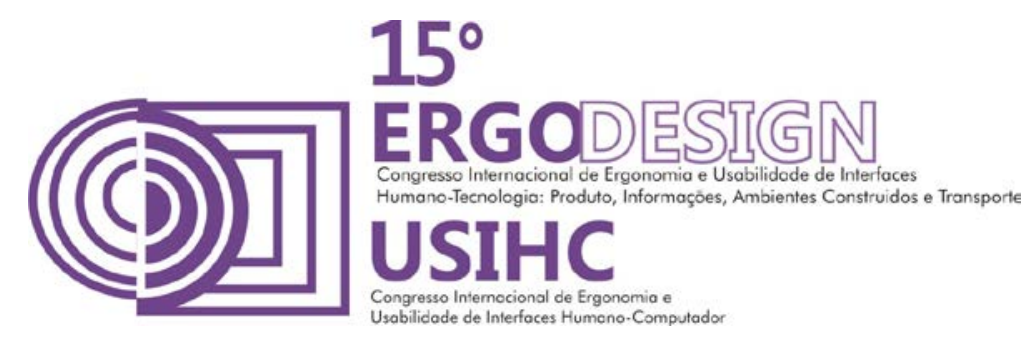

descrever seu próprio modelo de projetação, alterando ênfase em algum aspecto, mas mantendo sua essência. Deste modo pode-se concluir, a partir destes teóricos brasileiros, que o Partido Arquitetônico é a ideia inicial de um projeto, que a sua formulação é uma criação autoral e inventiva com base na coerência e na lógica funcional, e que, o partido, sendo uma prefiguração do projeto, faz da projetação um processo que vai do todo em direção à parte (BISELLI, 2011, WEB)

Talvez o ingrediente que torne os processos tão únicos e peculiares seja justamente as questões subjetivas da arquitetura que entram em algum momento na criação e que fascinam pelo desconhecido. (...) surge algo estranho que parece não caber na lógica cartesiana: a caixa preta; um conceito usualmente utilizado pelos arquitetos para significar o momento em que a subjetividade psicológica do arquiteto define, por meio de um rabisco (croqui) o partido do projeto (AMARAL, Cláudio Silveira, 2007 apud Biselli, 2011, WEB).

Para NEVES (1998), partido arquitetônico é a ideia preliminar do edifício projetado, a ideia inicial e inventiva. Idealizar um projeto requer, pelo menos, dois procedimentos: um em que o projetista toma a resolução de escolha dentre inúmeras alternativas, de uma idéia que deverá servir de base ao projeto do edifício do tema proposto; e outro em que a idéia escolhida é desenvolvida para resultar no projeto. É do primeiro procedimento, o da escolha da idéia, que resulta o partido, a concepção inicial do projeto do edifício, a feitura do seu esboço (NEVES, 1998, p. 15, apud BISELLI, 2011, WEB).

Nessa discussão, Biselli sugere novos caminhos ao buscar significados contemporâneos à discussão. Segundo ele, a expressão adoção do partido pressupõe erroneamente a sensação da pré-existência de todos os partidos adotáveis possíveis, como se as possibilidades de partido já estivessem sido catalogadas. Essa afirmação nos limitar a pensar que o projetista escolhe uma prefiguração do objeto a ser construído como ponto de partida (movimento do todo em direção à parte). Porém, inverter a lógica do raciocínio também é possível, se considerarmos projetos com tecnologias pré-moldadas (as partes precedem o todo). Neste caso, a tecnologia construtiva passa a ser o eixo central da ideia do projeto, que, apesar de um sistema poder enrijecer a configuração formal do projeto, o arquiteto sempre encontrará espaço para inserir seu pensamento.

Também é frequente observarmos nos discursos de arquitetos ao defenderem seus projetos haver uma justificativa para tal resultado baseadas principalmente na implantação da construção, com muito mais ênfase do que informações acerca das complexidades do programa ou informações e necessidades específicas de seus usuários. (HEYMANN, 2013).

Sob este aspecto, leva-se em conta dados e parâmetros físicos como o ângulo e o arco formado pelo movimento do sol no verão ou no inverno, a direção e velocidade dos ventos frios e quentes, fortes e suaves, úmidos e secos, altura da vegetação, localização e forma de formações rochosas, explicitar elementos como linhas de trem, caminhos, espécies ne vegetação, áreas construídas ao redor, confortantes, além de dos condicionantes físicos (dimensões da área) e legais (legislação do local), são algum deles. 


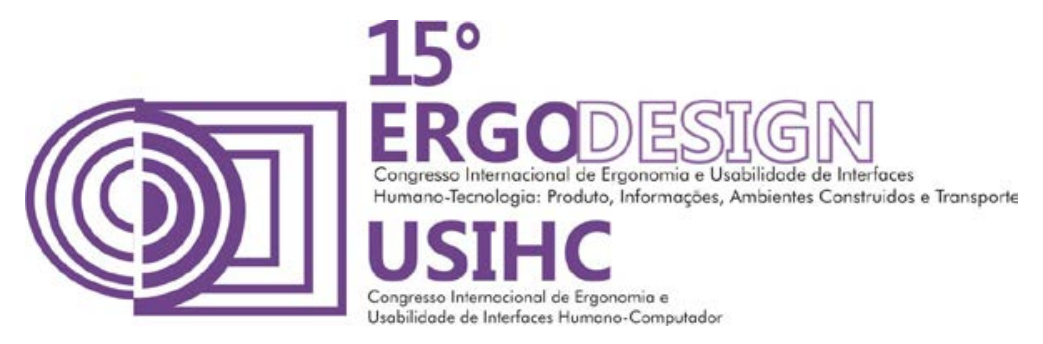

Entretanto tratar o problema do projeto sobre este viés dá a entender que o este seria o principal responsável pelo resultado obtido. É sem dúvida um caminho para se traduzir um importante significado cultural ao projeto, ainda que não seja garantia, levando a crer, equivocadamente, que se uma paisagem é boa, e a arquitetura é a paisagem (ou inspirada nela), logo a arquitetura e boa.

Outros exemplos de configurações bastante rígidas podem ser os projetos de fábricas, estádios ou aeroportos, por exemplo. Nestes casos, o partido arquitetônico pode ser estabelecido através de ênfases diversas, como por exemplo o enfoque no design biomimético ou a pré definição de um material que norteia a ideia arquitetônica.

Exemplos mais recentes, principalmente em grandes escritórios de ponta em países desenvolvidos, são as posturas mais contemporâneas de empresas que adotam um projeto mais exploratório e contínuo em sua forma, sem objetivos determinados, graças com o auxílio de softwares específicos e tecnologia de ponta, como o caso do Guggenheim Museum de Frank Gehry². É possível concluir portanto que o partido arquitetônico, ou ideia central de um projeto, pode ter origens diferentes durante o processo projetual, podendo nascer no inicio, durante o processo, anteceder o processo ou ainda ser formulado após o processo, sendo adotado (como no caso de alguns arquitetos teóricos, cujas reflexões se aplicarão na prática ou pela experiência quando familiarizados com a situação de partido de um outro projeto já conhecido); inventado (quando no início do processo) ou formulado (no sentido de aparecer ao longo da atividade de projeto).

Contudo, em nenhum caso verificou-se uma etapa que agregou o usuário no processo. São relatos que mais se assemelham a ações isoladas do ato criativo de interpretações pessoais do autor frente às informações obtidas para elaboração do projeto. Fica claro que o modo como cada arquiteto projeta torna-se menos relevante do que o resultado final do seu trabalho. A sua metodologia, que é sempre particular, tem um interesse menor neste momento.

\section{IMERSÃO, SUBJETIVIDADE E DESENHO: CONTRIBUIÇÕES DO DESIGN.}

A sociedade contemporânea trouxe uma série de aspectos e necessidades a respeito da concepção e das metodologias relacionadas ao ato de projetar, ampliando relações e estabelecendo uma série de elementos que passam a definir as áreas criativas contemporâneas. Mas como mencionado anteriormente, as disciplinas em arquitetura parecem ter estacionado quando estudamos novas abordagens sobre o tema, o que não aconteceu no design, que, entre outras metodologias, passou a contar também com a participação e coautoria do usuário no processo criativo como forma de melhorar a prática projetual.

De certa forma, esse desejo de mudança está levando os arquitetos, urbanistas e designers a desenvolverem projetos mais humanos e novos espaços públicos com um espírito mais democrático e inteligente. Pois, como alerta Bonsiepe (2011), até mesmo o Design perdeu substância quando passou a tratar das superficialidades, colocando-se a serviço da beleza cosmética e visando alcançar os lucros do mercado de maneira fácil.

\footnotetext{
${ }^{2}$ Arquiteto canadense, vencedor do Prémio Pritzker, em 1989.
} 


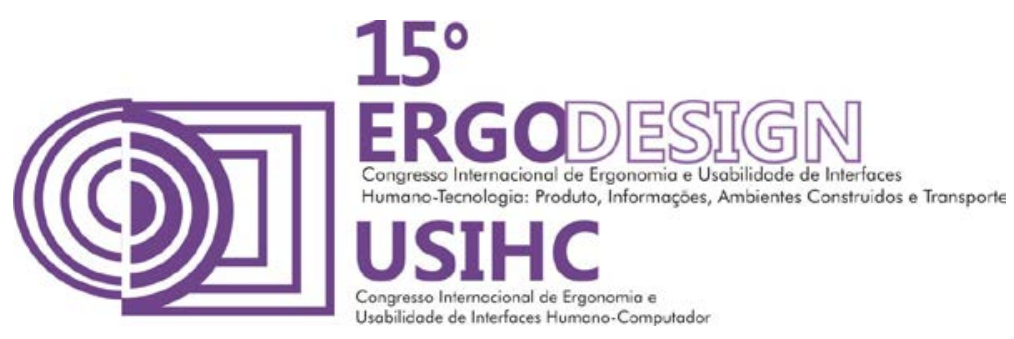

É necessário, portanto, atentar-se aos novos movimentos que surgem neste atual cenário de transição. Uma clara conscientização sobre atitudes e o espaço que vivemos, surgindo assim uma corrente de pensamento que tem como plano de fundo a criação de identidades, processos e metodologias criativas que se apropriem de certos códigos e valores que privilegiem o ser humano e celebrem a cidade. Ou em outras palavras promovam valores de cidadania através de uma nova dinâmica entre marcas ou produtos e as pessoas. É o que se chama de Design Centrado no Usuário (human-centerd design).

Liderada pelo Design no final da década de 90, uma revolução no modelo de consumo modificou o status quo das marcas, produtos e empresas. O modelo baseado na criação de marcas cujo objetivo era gerar desejo pela aspiração, tendo seu foco nos produtos, deu lugar a novas abordagens. Os bens materiais viraram interfaces, passando a ser possibilidades de interação que promovam algum tipo de serviço ao consumidor e que, portanto, precisam ser pensados à partir do ponto de vista das pessoas. Um modelo centrado no usuário, que ressignificou toda cadeia de produção e consumo.

Essa mudança faz com que as marcas colocassem o consumidor como centro, e adotassem ações no lugar de discursos, diálogos no lugar de propaganda e um espirito colaborativo e de co-criação no lugar da inovação fechada.

Um contexto de rede que deu poder às pessoas para transformar e agir com mais frequência por meio de iniciativas coletivas que buscam melhorar o ambiente ao seu redor, e acima de tudo utilizem tecnologias colaborativas, conectadas, que preservem e enriqueçam os laços entre as pessoas.

Segundo Sanders (2002) existe hoje uma mudança de um processo de design centrado no usuário para a de um processo no qual o usuário é um participante das experiências de cocriação. É uma mudança de atitude na qual se deixa de projetar para os usuários e passa-se a projetar com os usuários. Trata-se de um movimento que vai exigir novas formas de pensar, sentindo e trabalhando. "Experiência participativa não é simplesmente um método ou um conjunto de metodologias, é uma mentalidade e uma atitude sobre as pessoas. É a crença de que todas as pessoas tem algo a oferecer para o processo de projeto e que pode ser tão articulado e criativo quanto, quando administrado com as ferramentas apropriadas (Sanders, 2002, WEB)

As transformações tecnológicas que se proliferam de forma célebre estão criando uma nova cultura, cada vez mais visual, que está transformando nossa maneira de interagir com os objetos, as pessoas e o meio ambiente. O resultado de um projeto de Design pensado no âmbito do usuário, exerce um impacto cultural e influencia nossas experiências. Este impacto afeta a maneira pela qual as pessoas se relacionam com os artefatos, com as outras pessoas, com o meio ambiente e contribui para a criação de um consenso cultural. 


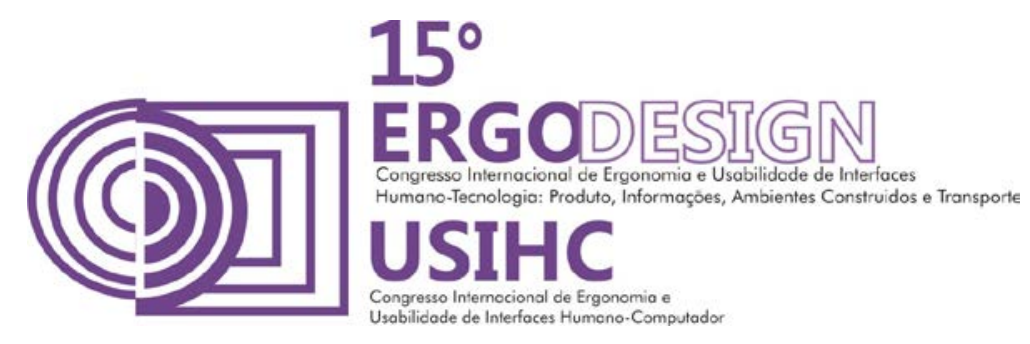

Diante disso, Sanders vai além ao investigar duas abordagens distintas para as pesquisas em design centrado no ser humano: a pesquisa que informa o processo de desenvolvimento do projeto e pesquisa que inspira o processo de desenvolvimento do projeto ${ }^{3}$.

Dessa forma os designers vão se aproximando cada vez mais perto dos futuros usuários para os quais estão projetando. Para Brown (2010) o Design Thinking vai além da habilidade que os designers têm por estabelecer a correspondência entre necessidades humanas, recursos tecnológicos e restrições práticas. Significa, colocar esse conhecimento nas mãos de pessoas que muitas vezes jamais se imaginaram nesse papel. Não se trata de elaborar propostas apenas centradas no ser humano; ela são profundamente humanas pela própria natureza, carregadas de significado emocional além do funcional.

Para Portugal (2013), as diferentes disciplinas de Design estão cada vez mais envolvidas em projetos que requerem um conjunto de competências, através experiências de equipes interdisciplinares, com o intuito de formar designers, não apenas relacionados com a habilidade e capacidade de projetar objetos, mas também através da forma de abordar os problemas ou métodos de trabalho que geralmente leva a inovação,

Essas abordagens do design são como escolher o caminho do meio, entre opções baseadas em sentimento, intuição e inspiração de um lado e fundamentos racionais ou analíticos de outros.

Neste sentido talvez o design tenha evoluído no desenvolvimento de novas áreas ou especialidades ao criar novas abordagem e metodologias criativas. Na essência da arquitetura, apesar buscar soluções que satisfaçam as necessidades humanas, mesmo quando existe uma reflexão mais assertiva sobre a cidade, a evolução aconteceu mais no campo tecnológico, com novos softwares capazes de materializar as formas inimagináveis de serem executadas há alguns anos atrás. Porém, parece ser que a arquitetura insiste em dar ideias, ao contrário do design, focado em buscar solução. O que é o "desejo" na arquitetura pode ser considerado o "problema" para o design. As imersões realizadas pelo design na busca de uma solução ao problema, tendo o ser humano no centro do processo não lembram em nada às metodologias de projeto arquitetônico tradicionais, as quais, a pesar de teoricamente pensar no homem, tendem a se limitar a analisar os condicionantes de um projeto, como: insolação, terreno, orçamento e legislação, por exemplo.

Esses atos de extrema imersão no contexto do projeto podem ser fundamentais para obter resultados interessantes. Em uma concorrência para a o edifício Audrey Jones Beck, uma extensão do Museum of Fine Arts de Houston, Rafael Moneo autor do projeto, cuja obra foi concluída em 2000, desbancou mestres da arquitetura como Tadao Ando ${ }^{4}$, Richard Meier ${ }^{5}$ e

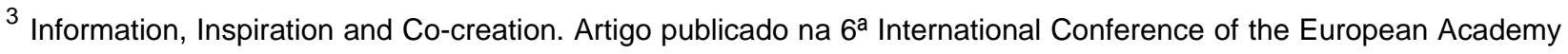
of Design, 2005,University of the Arts, Bremen, Alemanha.

${ }^{4}$ Tadao Ando (1941) é arquiteto japonês, Prêmio Pritzker em 1995 (Pritzker Prize, web).
} 


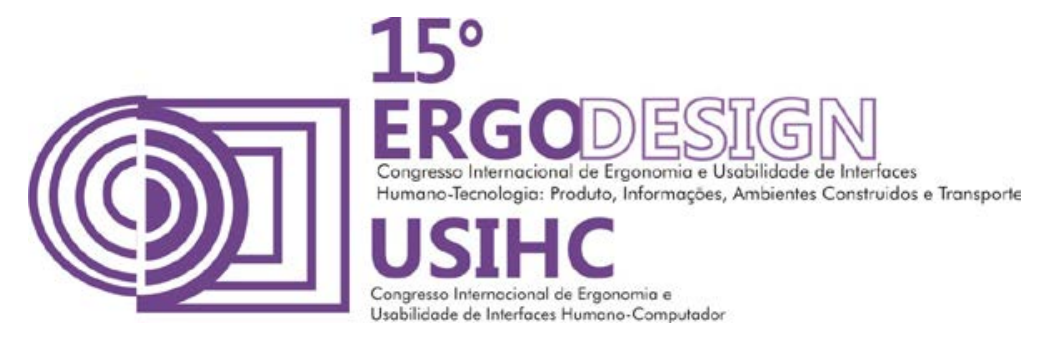

Robert Venturi ${ }^{6}$. Está localizado num complexo contexto da malha urbana, rodeado por exemplares muito peculiares. A escolha de Moneo para elaborar o projeto poderia ter sido justificada por sua habilidade em trabalhar com parâmetros contextuais difíceis, mas apesar de todos os demais arquitetos terem passado muito tempo observando e estudando o lugar, Moneo foi o único que pediu para ver a coleção (LEATHERBARROW, 2014).

Kahn (1986) afirmava que ainda que os clientes paguem para receber respostas, a pesquisa arquitetônica depende das perguntas, como faz o Design. Uma boa pergunta é mais importante porque as perguntas estendem uma ponte entre o que Kahn chamou de as dimensões mensuráveis e imensuráveis em arquitetura, como a distinção entre o que são edifícios e o que é arquitetura.

David Leatherbarrow (2014), em seu ensaio sobre a atividade da pesquisa projetual, aborda uma metodologia de projeto no escritório de Louis Kahn, exemplificada através de um trabalho específico. Comenta que a auto-inspiração que Kahn propunha dependia de diálogo. Para isso, transformava seu processo de projetual em uma espécie de seminários formados porestudantes e outros colegas profissionais, entre eles, além de arquitetos, um engenheiro e um escultor, interdisciplinaridade metodológica que se observa hoje em disciplinas do design.

Para Kahn, um grupo formado por profissionais atípicos em uma banca examinadora de projetos, era fundamental. As discussões no escritório de Kahn, como as trocas de ideias ajudavam a resolver os desafios arquitetônicos, através dos quais diferentes pontos de vista de profissionais ofereciam condições propicias para o desenvolvimento das ideias. $O$ engenheiro $e$ o artista não estavam ali como arquitetos. Eram incluídos porque tipicamente enfocavam-se sobre aspectos dos projetos que Kahn considerava essenciais mesmo que não fossem manifestamente arquitetônicos (Kahn, 1972).

Em um tema que utilizou para orientar esse diálogo da pesquisa Kahn exemplificou certa vez uma das premissas metodológicas essenciais em seu trabalho: com o objetivo de propor o projeto de um monastério, Kahn solicitou a seus alunos como ponto de partida que se refletisse acerca de assuntos primários: se o problema era um monastério, deveriam assumir que não existia nenhum monastério, esquecendo a palavra monge, refeitório, capela ou cela, por exemplo. Com isso Kahn demonstrava que no resultado obtido em suas aulas ou ateliers a originalidade de pensamento que evidenciavam os projetos não teriam sido possíveis de houvesse dado aos estudantes um programa específico e detalhado dos requisitos.

Os resultados até poderiam ser diferentes entre si em termos de configurações, planificações ou proporções, mas seus requisitos básicos eram os mesmo, como a busca princípios de associações, por comportamentos, sensações ou estado de espirito nos projetos eram os mesmos, como contemplação em isolamento, aprendizagem, ritual, interação, relação com exterior, etc.

\footnotetext{
${ }^{5}$ Richard Meier (1934) é arquiteto americano, Pritzker em 1984 (Pritzker Prize, web).

${ }^{6}$ Robert Charles Venturi (1925) é arquiteto americano, Prêmio Pritzker em 1991 (Pritzker Prize, web).
} 


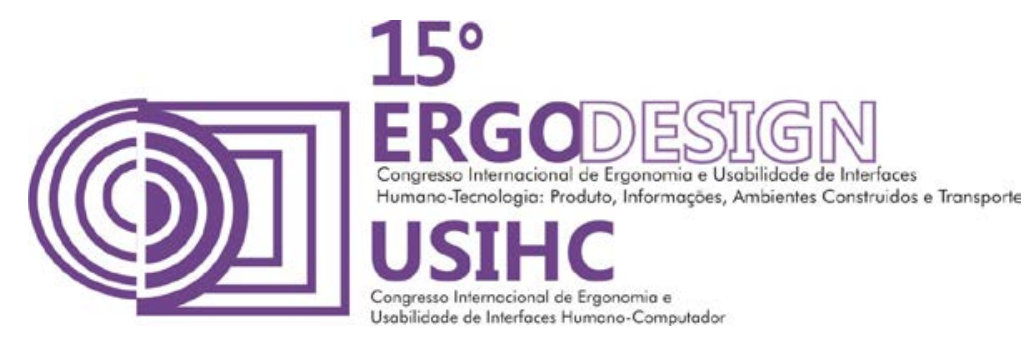

Assemelhando-se aos processos de Design Thinking e a abordagem de Cross (2004), o pensamento do arquiteto, neste caso, tornava-se tangível em muitas folhas de papel como método de trabalho. Busca de começos, usando com ponto de partidas condições específicas, renovando os começos. Seus ajudantes passavam a maior parte do tempo desenhando estudos repetidamente, numa atmosfera que se assemelhava mais em um estúdio do que em um escritório de arquitetura.

Pode se dizer que a repetição dos desenhos são os instrumentos para o a cada tentativa surja uma nova possibilidade, ocasionalmente uma nova repetição. As portas permanecem abertas para que algo inesperado e melhor que a resposta que parecia tão óbvia (LEATHERBARROW, 2014).

\section{CONSIDERAÇÕES FINAIS}

Percebe-se que a área do design está se aproximando cada vez mais perto dos futuros usuários para os quais estão projetando. As implicações dessa mudança para a educação dos designers e pesquisadores são enormes e está mudando a paisagem da prática do design, bem como, a criação de novos domínios da criatividade coletiva. Espera-se que esta evolução apoie uma transformação em direção a formas mais sustentáveis de vida no futuro.

A exemplo do design, espera-se que a arquitetura também possa incluir o ser humano no centro de seus processos criativos. Tê-lo no centro do processo faz com que este se torne mais crítico e exija posturas mais ativas, valorizando aquelas instituições que não somente forneçam produtos ou serviços, mas que gerem mudanças e transformações significativas e factíveis, próximas da realidade cotidiana das pessoas. São criações que, sejam ou não lucrativas para seus donos, são radicalmente transformadores de nossa sociedade.

A experiência humana está a cada dia mais exposta a estímulos, sejam eles visuais ou sensoriais, e entende-la tornará as pessoas mais criteriosas e informadas nos processos de tomada de decisão. Tanto o Design como a Arquitetura, em sua função de natureza projetual, podem influenciar a formação de uma cultura crítica como um todo. É de suma importância frisar que este trabalho, ao abordar novas metodologias de desenvolvimento de projeto e processos criativos baseados não visa identificar uma melhor maneira de se fazer as coisas, mas sim refletir sobre modos diferentes de se fazê-lo, tendo como base a observação do movimento da sociedade e seus comportamentos atuais. Por fim, espera-se contribuir na questão dos processos multidisciplinares à luz das complexidades atuais do processo criativo, dos cenários tecnológicos e comportamentais, disponibilizando reflexões sobre formas de melhorar a prática projetual da arquitetura pelo viés do Design, abordando aspectos de interação e criação de experiências enriquecedoras.

\section{REFERÊNCIAS BIBLIOGRÁFICAS}

BISELLI, Mario. Teoria e prática do partido arquitetônico. Disponível em http://www.vitruvius.com.br/revistas/read/arquitextos/12.134/3974>. Acesso em: 11 de julho 2014.

BONSIEPE, Gui. Design como prática de projeto. São Paulo: Blucher, 2012. 


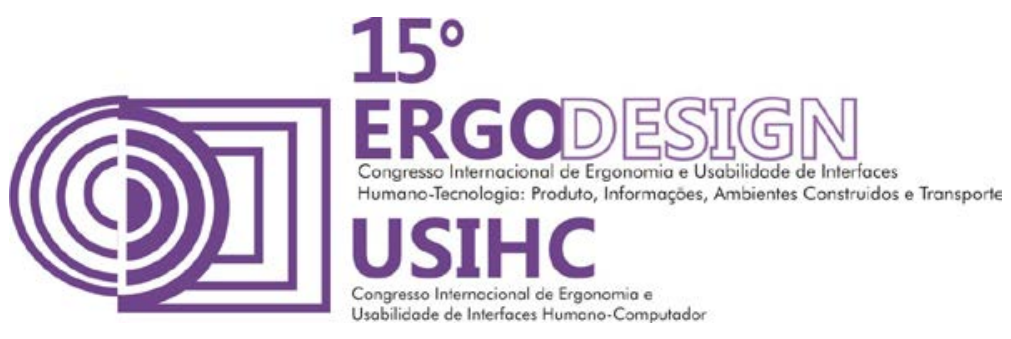

Design, Cultura e Sociedade. São Paulo: Blucher, 2011.

BROWN, Tim. Design Thinking: uma metodologia poderosa para decretar o fim das velhas ideias. Rio de Janeiro: Elsevier, 2010. $3^{\mathrm{a} e d .}$

CROSS, Nigel. Desenhante. O pensador do desenho. Santa Maria: sCHDs, 2004.

HEYMANN, David. A paisagem é como sexo. Revista Summa, Buenos Aires, n. 126, p. 94-103, janeiro. 2013.

KAHN, Lousi I. "How'ml Doing, Corbusier", (1972) em LATOUR. Alessandra (ed.). Louis I Kahn. Writings, Lectures, Interviews. Nova lorque: Rizzoli, 1991, pp. 297-312.

KAHN, Lous. "The Profession and Education", em WURMAN, Richard Saul. What Will Be has Always been. Nova lorque: Rizzoli, 1986, p.92.

KAHN, Louis. "Signature Against the Sky" (1967), em Eye on Art "Signature agaist the sky", a portrait of Louis I. Kahn, architect; produzido por WCAU-TV Filadelfia.

LERNER, Jaime. Acupuntura urbana. Rio de Janeiro: Record, 2003.

LEATHERBARROW, David. Recomeçando: a atividade da pesquisa projetual. Revista Summa, Buenos Aires, n. 134, p. 88-93, março. 2014.

MAHFUZ, Edson da Cunha. Reflexões sobre a construção da Reflexões sobre a construção da Reflexões sobre a construção da Reflexões sobre a construção da forma pertinente. Disponível em < http://www.vitruvius.com.br/revistas/read/arquitextos/04.045/606>. Acesso em: 11 de julho 2014. julho 2014.

MAHFUZ, Edson da Cunha. Arquitetura é Arte? Revista Summa, Buenos Aires, n. 134, p. 128, março. 2014.

PIRONDI, Ciro. Um desenho sobre as incertezas. Revista Móbile, São Paulo: CAU/SP, p. 29.

SANDERS, E. B.; BRANDT, E.; BINDER, T. A framework for organizing the tools and techniques of Participatory Design. Sydney, Austrália. Artigo, 2010.

SANDERS, Elizabeth B. Prototyping for the design spaces of the future. 2013.

SANDERS, Elizabeth. STAPPERS, Pieter. Co-cration and the new ladscapes of design. In CoDesign, Taylor \& Francis, 2008. Disponível em http://journalsonline.tandf.co.uk. Acesso em julho de 2014.

SEGAWA, Hugo. Saberes e fazeres na arquitetura. Revista Móbile, São Paulo: CAU/SP, p. 28, n. 1, junho. 2014. EVERLING, Marli, T. Diretrizes Para Um Ambiente de Aprendizagem Assíncrona no Curso de Design. Tese de Doutorado. Rio de Janeiro: PUC-Rio. 2011. 46-47

SUDJIC, Deyan. A linguagem das coisas. Rio de Janeiro: Intrínseca, 2010. 